BMJ Open Diabetes Research \& Care

\title{
Psychological barriers to optimal insulin therapy: more concerns in adolescent females than males
}

\author{
Line Wisting, ${ }^{1,2}$ Lasse Bang, ${ }^{1}$ Torild Skrivarhaug, ${ }^{2,3,4,5}$ Knut Dahl-Jørgensen, ${ }^{2,4,5}$ \\ Øyvind $\mathrm{R} \varnothing^{1,6}$
}

To cite: Wisting L, Bang L, Skrivarhaug $\mathrm{T}$, et al. Psychological barriers to optimal insulin therapy: more concerns in adolescent females than males. BMJ Open Diabetes Research and Care 2016;4:e00203. doi:10.1136/bmjdrc-2016000203

Received 28 January 2016 Revised 18 April 2016 Accepted 2 May 2016

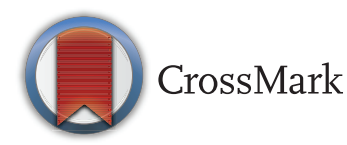

${ }^{1}$ Division of Mental Health and Addiction, Regional Department for Eating Disorders, Oslo University Hospital, Oslo, Norway ${ }^{2}$ Oslo Diabetes Research Centre, Oslo University Hospital, Oslo, Norway ${ }^{3}$ Department of Pediatric Medicine, The Norwegian Childhood Diabetes Registry, Oslo University Hospital, Oslo, Norway

${ }^{4}$ Department of Pediatric Medicine, Oslo University Hospital, Oslo, Norway

${ }^{5}$ Faculty of Medicine, University of Oslo, Oslo, Norway

${ }^{6}$ Division of Mental Health and Addiction, Institute of Clinical Medicine, University of Oslo, Oslo, Norway

Correspondence to

Line Wisting;

line.wisting@ous-hf.no

\section{ABSTRACT}

Objective: The aim of this study is to investigate psychological barriers (illness perceptions, insulin beliefs, and coping strategies) to optimal insulin therapy among adolescents with type 1 diabetes (T1D), with a specific focus on gender differences and mode of treatment (insulin pump vs pen).

Methods: A total of 105 males and females (12-20 years) participated in this study. The Brief IIIness Perception Questionnaire, the Beliefs about Medicines Questionnaire, and the Adolescent Coping Orientation for Problem Experiences were completed. Additionally, diabetes clinical data were collected by the Norwegian Childhood Diabetes Registry.

Results: Females had significantly more negative illness perceptions than males on all dimensions $(p<0.05)$, with moderate-to-large effect sizes. Regarding insulin beliefs, females scored significantly higher than males on insulin concern $(p<0.001)$, indicating more concerns about insulin. There were no significant gender differences on perceptions of insulin necessity. Finally, females scored significantly higher on the coping strategies being social and solving family problems $(p<0.01)$, indicating more positive coping among females than males for these subscales. In terms of treatment mode, the only statistically significant difference in the psychological aspects was for the illness perception treatment control, with patients using insulin pen reporting more negative perceptions on this dimension than patients using insulin pump.

Conclusions: Addressing psychological aspects may be a clinically important supplement to standard somatic T1D care. The consistent finding of gender differences across the psychological measures implies that a tailored treatment approach for males and females with T1D may be warranted.

\section{INTRODUCTION}

Childhood-onset type 1 diabetes (T1D) is an international priority associated with vast individual burden and societal costs. Treatment of T1D is largely based on self-care, as the patients themselves need to monitor and regulate blood glucose levels and adjust the insulin dose according to various factors, including blood glucose, food intake, emotional state, and physical activity. This is a

\section{Key messages}

- The current article provides descriptive data on insulin beliefs, illness perceptions, and coping strategies in adolescents with type 1 diabetes.

- Young females were generally found to be more concerned regarding their type 1 diabetes and insulin therapy than males.

- Patients using insulin pen reported more negative perceptions of treatment control than patients using insulin pump.

demanding and continuous regulation task, placing major responsibility on the young individuals with T1D and their families. Adolescence is a particularly challenging period due to the gradual transfer of treatment responsibility from the parents to the young patients themselves. ${ }^{1}$ Adolescents with T1D have been found to suffer from more psychological problems than non-diabetic peers, including depression, ${ }^{2}{ }^{3}$ anxiety, ${ }^{4}$ and eating disorders. ${ }^{5-7}$ Additionally, key clinical outcomes such as metabolic control (measured by glycated hemoglobin (HbAlc) $)^{8}$ and eating disorder psychopathology ${ }^{9}$ have been shown to be significantly related to psychological aspects, including illness perceptions, insulin beliefs, and coping strategies.

Illness perceptions refer to the individual's experience and beliefs about their illness and are found to be associated with outcome in a variety of somatic and psychological illnesses, including cancer, ${ }^{10}$ cardiovascular diseases, ${ }^{11}$ chronic fatigue syndrome, ${ }^{12}$ eating disorders, ${ }^{13}$ and T1D. ${ }^{14} 15$ Although previous research have reported more negative illness perceptions in females than males in the context of other illnesses, ${ }^{16}{ }^{17}$ no studies have, to the best of our knowledge, investigated this in adolescents with T1D.

Insulin beliefs refer to individual perceptions or attitudes toward insulin. Insulin beliefs have been found to be associated with adherence to treatment ${ }^{18} 19$ and diabetes control. $^{20}$ Additionally, insulin concerns have 
been found to be significantly correlated with insulin restriction motivated by weight and shape concerns, and linked to eating disorder psychopathology. ${ }^{9}$

Coping strategies (behaviors adopted to handle negative or stressful events) have been reported to be associated with metabolic control among adolescents and adults with T1D. For example, greater use of emotionfocused coping styles is found to be significantly associated with poorer metabolic control. ${ }^{21}$

Gender differences in psychological aspects have previously been suggested from a theoretical perspective, commonly by means of socialization theory and the roleconstraint theory (hypothesizing that traditional socialization patterns and gender roles influence how males and females cope with stress). ${ }^{22}{ }^{23}$ Also, prior research has documented significant gender differences in the association between psychological aspects and HbAlc, ${ }^{8}$ as well as eating disorder psychopathology. ${ }^{9}$ In these studies, psychological aspects were significantly associated with HbAlc and eating disorder psychopathology among adolescent females, but not among males. Furthermore, mode of treatment (insulin pump vs pen) has been found to impact HbAlc. ${ }^{24}$ To the best of our knowledge, no studies have previously investigated gender differences or mode of treatment in terms of psychological aspects among adolescents with T1D. Greater knowledge about such potential psychological barriers to important clinical outcomes may potentially inform treatment innovation and address the issue of whether interventions should be specifically tailored according to gender and mode of treatment.

Consistent with data from Hilliard et $a l^{25}$ and Petitti et $a l,{ }^{26}$ only one-third of adolescents in the Norwegian Childhood Diabetes Registry (NCDR) manage the international targets of HbAlc values $<7.5 \% .{ }^{27}$ Given that psychological aspects have been shown to be significantly associated with key outcomes such as HbAlc, investigating psychological barriers to treatment in young males and females with T1D may both improve our understanding of patient self-care and subsequent metabolic control, and ultimately, improve the poor prognosis associated with childhood-onset T1D.

\section{Aim of study}

The aim of this study is to investigate potential psychological barriers (illness perceptions, insulin beliefs, and coping strategies) to optimal insulin therapy among adolescents with T1D, with a specific focus on gender differences and mode of treatment. It is anticipated that adolescent females are more concerned than males; specifically, we hypothesize that females display more negative illness perceptions than males.

\section{MATERIALS AND METHODS \\ Participants and procedure}

As described in previous studies, ${ }^{8}{ }^{9}$ the NCDR is a nationwide, population-based registry, which includes all newly diagnosed children with diabetes since 1989 . In the Norwegian healthcare system, all children aged 0-14.9 years with suspected diabetes are referred to a pediatric department. All pediatric departments in Norway perform and report the results of annual standardized examinations to NCDR. Thus, patients with T1D in the NCDR are recruited from hospitals around Norway and across a large geographic area. The current study is part of a larger project of the NCDR, which included 850 participants aged 12-20 years. Between 2011 and 2012, these 850 individuals were invited to participate in an assessment of psychological aspects. The assessment was conducted at Oslo University Hospital or another location of the participants' choice (usually their home or school).

A subset of 105 individuals (12\%) agreed to participate by returning a signed consent form via postal mail. Table 1 illustrates sample characteristics. Participants resided in rural and urban settings across all geographical regions of Norway. A total of $65.3 \%$ of the participants used insulin pumps and $33.7 \%$ used pen. There were $44(41.9 \%)$ males and $61(58.1 \%)$ females. Male and female participants did not differ significantly on age (years), HbAlc, age-adjusted and gender-adjusted body mass index (zBMI), age of onset, duration of diabetes illness (years), or mode of treatment (pump vs pen). Participants were compared with the background T1D population in the NCDR, which has a completeness of $95 \%$ (24). No differences were found for age, zBMI, T1D duration, number of consultations with the diabetes team, number of consultations with dieticians, or mode of treatment. Participants were slightly older at the onset of T1D than the background NCDR population (9.6 vs 8.8 years, $\mathrm{p}<0.05)$, had somewhat lower HbA1c $(8.6 \%$

\section{Table 1 Participant characteristics}

\begin{tabular}{|c|c|c|c|c|c|}
\hline & All & Males & Females & p Value & Effect size \\
\hline $\mathrm{n}$ & 105 & 44 & 61 & & \\
\hline Age (years) & $15.7(1.8)$ & $15.9(1.8)$ & $15.6(1.8)$ & NS & 0.2 \\
\hline $\mathrm{HbA1c}(\%)$ & $8.6(1.3)$ & $8.4(1.3)$ & $8.7(1.3)$ & NS & -0.2 \\
\hline zBMI & $0.4(0.8)$ & $0.3(0.8)$ & $0.4(0.9)$ & NS & 0 \\
\hline Diabetes duration (years) & $5.7(3.7)$ & $5.7(3.6)$ & $5.7(3.7)$ & NS & 0 \\
\hline Age at onset of diabetes (years) & $9.6(3.5)$ & $9.8(3.6)$ & $9.5(3.5)$ & NS & 0.1 \\
\hline
\end{tabular}

Data are mean (SD). $p$ Value $>0.05=N S$. Effect size Cohen's $d$.

zBMI, age-adjusted and gender-adjusted body mass index; HbA1c, glycated hemoglobin; NS, non-significant. 
(70 $\mathrm{mmol} / \mathrm{mol})$ vs $8.9 \%(74 \mathrm{mmol} / \mathrm{mol}), \mathrm{p}<0.05)$, and had fewer episodes of diabetes ketoacidoses $(0.02$ vs $0.05, \mathrm{p}<0.05)$. However, the effect sizes were small $(0.2$, -0.2 , and -0.2 , respectively).

\section{Ethical aspects}

The regional ethics committee approved the study. Written informed consent was obtained from all participants and their parents if the participant was below the age of 16 years.

\section{Measures \\ The Brief IIIness Perception Questionnaire (BIPQ)}

The $\mathrm{BIPQ}^{28}$ is a brief version of the Illness Perceptions Questionnaire (IPQ) ${ }^{29}$ and Illness Perceptions Questionnaire-Revised (IPQ-R), ${ }^{30}$ and is a valid and reliable measure of illness perceptions. ${ }^{28}$ It has been used in the context of a variety of illnesses, including T1D. It consists of nine items, and each item assesses one dimension of illness perceptions: consequences (perceived consequences of the illness), timeline (for how long the person believes the illness will last), personal control (the extent to which the patient perceive they can control or cure the illness), treatment control (whether the patient believe that the treatment can control or cure the illness), identity (the label people use to describe the illness and accompanying symptoms), coherence (whether the person feels they understand the illness), emotional representation (whether the illness affects the patient emotionally), concern (if the patient is concerned about the illness), and causation (perceived causes of the illness). Items 1-8 are used in this study (item 9 (causation), an open-ended question tapping perceptions of T1D causes, was excluded). Answers range from 0 to 10 , and higher scores indicate more threatening/negative views of their T1D (after items 3, 4, and 7 are reversed).

\section{The Beliefs about Medicines Questionnaire (BMQ)}

The $\mathrm{BMQ}^{31}$ is a measure of beliefs about medicines in general, and one specific medicine (insulin in this study). It consists of four subscales: specific (insulin) necessity, specific (insulin) concern, general necessity, and general overuse. Answers range on a five-point Likert scale, ranging from $1=$ strongly disagree to $5=$ strongly agree. The two specific subscales were employed in this study, and higher scores indicate stronger perceptions of the concerns and necessity of insulin. A Norwegian version has been translated and validated, demonstrating satisfactory internal consistency (Cronbach's $\alpha$ of 0.76 and 0.90 for specific concern and necessity, respectively). ${ }^{32}$

\section{The Adolescent Coping Orientation for Problem Experiences (ACOPE)}

The $\mathrm{ACOPE}^{33}$ is a measure of coping strategies and is translated and validated for use among Norwegian adolescents. ${ }^{34}$ In addition to a total score indicating the overall degree of positive coping, the ACOPE consists of 34 items divided in five subscales: being social, seeking diversions, ventilating negative feelings, developing selfreliance, and solving family problems. The Norwegian version of the ACOPE demonstrated satisfactory psychometric properties, with Cronbach's $\alpha$ of the subscales ranging from 0.72 to 0.82 . Answers range from 1 to 5 (never, seldom, sometimes, often, usually), and higher scores are operationalized as a higher degree of positive coping on all subscales after item numbers 8 and 24, as well as the subscale 'ventilating negative feelings', are reversed.

\section{Clinical data}

Clinical data were obtained from NCDR. HbAlc was determined for all participants by high-performance liquid chromatography (Tosoh G7; Tosoh Europe N.V., Belgium). All samples were analyzed in the same central laboratory and standardized according to the Diabetes Control and Complications Trial standards. The reference range was $4.0-6.0 \%$; the analytical coefficient of variation was $<1 \%$.

$z B M I$ is age-adjusted and gender-adjusted BMI. BMI was calculated based on weight and height $\left(\mathrm{kg} / \mathrm{m}^{2}\right)$ and standardized to a z-score according to age and gender using the Centers for Disease Control and Prevention Growth Charts 2000, since the participants were primarily below 18 years. ${ }^{35}$

\section{Statistical analyses}

Illness perceptions, coping strategies, and insulin beliefs were described as means and SDs. Independent samples Student's t-tests were carried out to investigate whether differences according to gender and mode of treatment were significant. Effect sizes were calculated by means of Cohen's $\mathrm{d}$, and the guidelines used for interpreting this value were: $0.20=$ small effect, $0.50=$ moderate effect, and $0.80=$ large effect. ${ }^{36}$ Statistical analyses were conducted using PASW V.21 (SPSS IBM, New York, New York, USA).

\section{RESULTS}

\section{Participant characteristics}

Table 1 illustrates sample characteristics. Mean age of the 105 participants was 15.7 years (SD 1.8) and age at onset of T1D was 9.6 years (SD 3.5). Mean T1D duration was 5.7 years (SD 3.7), mean zBMI was 0.4 (SD 0.8), and mean $\mathrm{HbAlc}$ was $8.6 \%(70 \mathrm{mmol} / \mathrm{mol}$; SD 1.3$)$. No significant gender differences were found for these sociodemographic and clinical characteristics.

\section{IIIness perceptions}

The mean overall BIPQ score was 28.5 (SD 9.3) for males and 39.7 (SD 11.3) for females. Mean scores for males and females on each of the eight items are presented in table 2 . Females had significantly higher negative perceptions of their T1D than males on all of the 


\begin{tabular}{|c|c|c|c|c|c|}
\hline & $\begin{array}{l}\text { All } \\
(n=105)\end{array}$ & $\begin{array}{l}\text { Males } \\
(n=44)\end{array}$ & $\begin{array}{l}\text { Females } \\
(n=61)\end{array}$ & Significance & $\begin{array}{l}\text { Effect } \\
\text { size }\end{array}$ \\
\hline $\begin{array}{l}\text { How much does your diabetes affect your life? } \\
\text { (Consequences) }\end{array}$ & $5.3(2.3)$ & $4.3(2.1)$ & $6.1(2.1)$ & 0.001 & -0.9 \\
\hline How long do you think your diabetes will continue? (Timeline) & $9.5(1.3)$ & $9.0(1.7)$ & $9.8(0.7)$ & 0.01 & -0.6 \\
\hline $\begin{array}{l}\text { How much control do you feel that you have over your } \\
\text { diabetes? (Personal control) }\end{array}$ & $2.5(2.0)$ & $2.0(1.5)$ & $2.9(2.2)$ & 0.05 & -0.5 \\
\hline $\begin{array}{l}\text { How much do you think your treatment can help your } \\
\text { diabetes? (Treatment control) }\end{array}$ & $2.3(2.1)$ & $1.8(1.8)$ & $2.6(2.2)$ & 0.05 & -0.4 \\
\hline $\begin{array}{l}\text { How much do you experience symptoms from your diabetes? } \\
\text { (Identity) }\end{array}$ & $4.4(2.4)$ & $3.2(1.8)$ & $5.3(2.4)$ & 0.001 & -1.0 \\
\hline How concerned are you about your diabetes? (Concern) & $3.7(2.6)$ & $2.6(2.3)$ & $4.5(2.5)$ & 0.001 & -0.8 \\
\hline $\begin{array}{l}\text { How well do you feel you understand your diabetes? } \\
\text { (Coherence) }\end{array}$ & $2.2(2.0)$ & $1.8(1.5)$ & $2.6(2.3)$ & 0.05 & -0.4 \\
\hline $\begin{array}{l}\text { How much does your diabetes affect you emotionally? } \\
\text { (Emotional representation) }\end{array}$ & $5.2(2.8)$ & $3.7(2.6)$ & $6.3(2.5)$ & 0.001 & -1.0 \\
\hline Overall score & $35.0(11.9)$ & $28.5(9.3)$ & 39.7 (11.3) & 0.001 & -1.1 \\
\hline
\end{tabular}

BIPQ items $(p<0.05)$, with moderate-to-large effect sizes ranging from -0.4 to -1.0 . Illness perceptions did not differ significantly according to mode of treatment, except for treatment control (ie, how much they think their treatment can help their T1D). Specifically, patients using insulin pen had significantly more negative views on treatment control than patients using pump (mean=2.9 (SD 2.2) vs 1.9 (SD 2.0), respectively, $\mathrm{p}<0.05)$, effect size 0.5 .

\section{Insulin beliefs}

Table 3 presents mean scores (SD) on the two specific subscales of the BMQ: insulin necessity and insulin concern. Females scored significantly higher than males on insulin concern $(p<0.001$, effect size -0.9$)$, indicating more negative perceptions/more concerns about insulin. Males and females did not significantly differ on their perceptions of insulin necessity. There were no statistically significant differences in insulin beliefs between patients treated with insulin pump versus pen.

\section{Coping strategies}

Mean scores for the subscale and total scores on the ACOPE is presented in table 4 . The mean total scores for males and females were 3.3 (SD 0.4) and 3.4 (SD
$0.4)$, respectively. The difference in total score between the genders was not significant (effect size -0.3 ). With regard to the subscales, females scored significantly higher on being social and solving family problems (both p's $<0.01$, effect size -0.8 and -0.6 , respectively), indicating more positive coping among females than males for these subscales. There were no statistically significant differences in coping strategies between patients treated with insulin pump versus pen.

\section{DISCUSSION}

This study investigated potential psychological barriers to optimal insulin therapy in male and female adolescents with T1D. Significant gender differences in illness perceptions, insulin concern, and social-coping and family-coping strategies were demonstrated. Specifically, females scored significantly higher than males on all illness perception dimensions, indicating that females generally held more negative views about their T1D than males. Although several studies have investigated illness perceptions among individuals with T1D, to the best of our knowledge, our study represents the first to specifically test gender differences in adolescents with T1D. A prior study of allergic rhinitis among adults with an average age of 35 years investigated gender

\section{Table 3 Insulin beliefs}

\begin{tabular}{llllll}
\hline & All $(\mathbf{n}=\mathbf{1 0 5})$ & Males $(\mathbf{n}=\mathbf{4 4 )}$ & Females $(\mathbf{n}=\mathbf{6 1 )}$ & Significance & Effect size \\
\hline Insulin necessity & $21.7(3.4)$ & $21.5(3.2)$ & $21.9(3.6)$ & NS & -0.1 \\
Insulin concern & $12.0(4.3)$ & $10.1(3.5)$ & $13.4(4.2)$ & 0.001 & -0.9 \\
\hline
\end{tabular}

Mean scores (SD) for males and females on beliefs about medicines in general (BMQ general) and insulin specifically (BMQ specific). Higher scores indicate stronger beliefs about the necessity and concern about insulin.

Data are mean and SD. $p$ Value $>0.05=N S$. Effect size Cohen's $d$.

$\mathrm{BMQ}$, Beliefs about Medicines Questionnaire; NS, non-significant. 
Table 4 Coping strategies

\begin{tabular}{lllllr}
\hline & All $(\mathbf{n}=\mathbf{1 0 5})$ & Males $(\mathbf{n}=\mathbf{4 4 )}$ & Females $(\mathbf{n}=\mathbf{6 1})$ & Significance & Effect size \\
\hline Being social & $3.3(0.8)$ & $3.0(0.8)$ & $3.6(0.7)$ & 0.01 & -0.8 \\
Seeking diversion & $3.1(0.7)$ & $3.1(0.6)$ & $3.0(0.7)$ & NS & 0.2 \\
Ventilating negative feelings & $3.7(0.6)$ & $3.8(0.6)$ & $3.7(0.7)$ & NS & 0.2 \\
Developing self-reliance & $3.8(0.5)$ & $3.8(0.5)$ & $3.9(0.5)$ & NS & -0.2 \\
Solving family problems & $2.8(0.7)$ & $2.6(0.7)$ & $3.0(0.7)$ & 0.01 & -0.6 \\
ACOPE total score & $3.4(0.4)$ & $3.3(0.4)$ & $3.4(0.4)$ & NS & -0.3 \\
\hline
\end{tabular}

Mean scores (SD) for males and females on the ACOPE subscale and total scores.

Data are mean and SD. $p$ Value $>0.05=N S$. Effect size Cohen's $d$.

ACOPE, Adolescent Coping Orientation for Problem Experiences; NS, non-significant.

differences using the BIPQ. Similar to our study, females generally perceived allergic rhinitis as a more threatening disease than males. ${ }^{17}$ Further, a study of illness perceptions among patients with cardiac disease (mean age 61 years) found that women perceived their illness to be more chronic and untreatable, while men perceived greater personal and treatment control. ${ }^{16}$ Despite broad differences in age and type of illness, these studies collectively indicate that females generally hold more negative views about their illness than males, yet more studies are needed to replicate these findings.

We also investigated whether differences in psychological aspects existed according to mode of treatment, that is, insulin pump versus insulin pen (injections). Interestingly, patients using insulin pens held significantly more negative perceptions of treatment control than patients using insulin pumps. This might be expected given that a meta-analysis ${ }^{24}$ found HbAlc to be significantly lower (better metabolic control) among adolescents treated with insulin pump versus insulin pens. The importance of perceptions of treatment control was demonstrated in a study of adolescents (aged 10.5-15.5 years) with T1D. Treatment control was found to moderate the relationship between negative affect and a number of T1D problems, including problems with high blood glucose, forgetting or skipping a blood glucose test, problems with low blood glucose, and problems in taking the wrong amount of insulin. ${ }^{37}$ Furthermore, a systematic review of illness perceptions in mental health (adults) found that positive perceptions of treatment control were linked to better treatment adherence. ${ }^{38}$ As such, treatment mode (insulin pump vs pen) may be relevant for important T1D outcomes via its association with treatment control and treatment adherence.

Insulin concerns are previously found to be associated with insulin restriction (reducing or omitting your insulin dose due to weight and shape concerns) and eating disorder psychopathology among adolescents with T1D. ${ }^{9}$ Insulin restriction and eating disorder pathology are significantly associated with poorer metabolic control and increased rates of morbidity and mortality, ${ }^{39}$ supporting the clinical importance of addressing insulin concern among young males and females with T1D. In the current study, we found that adolescent females scored significantly higher than males on insulin concern, indicating that more negative perceptions or greater concerns about insulin may be an important psychological barrier to optimal insulin therapy. No gender differences were found on the beliefs of insulin necessity. A previous study which investigated the BMQ in adults with T1D (aged 18-58 years, mean age 30 years) ${ }^{40}$ found much lower scores than our study. Specifically, they reported mean scores of 2.5 (SD 0.8) for insulin concerns and 4.3 (SD 0.6) for insulin necessity. In comparison, our mean scores (SD) were 12.0 (4.3) and 21.7 (3.4), respectively. However, the mean age of our adolescent sample was 15.7 years. Discrepant findings might indicate that adolescents generally hold stronger beliefs about both insulin necessity and concerns than adults. Adolescents may be more likely to experience distress associated with puberty itself, in addition to diabetesspecific stressors, contributing to differences in scores between adolescents and adults. Adolescence is usually the time where the daily responsibility for T1D treatment is transferred from parents to the young patients themselves, and this may lead to greater distress regarding insulin. ${ }^{1}$ This suggests that insulin beliefs, especially insulin concerns, may be particularly important to address among adolescents with T1D to facilitate positive attitudes to insulin and adequate insulin dosages. Sufficient insulin administration is crucial to prevent serious diabetes complications, yet rates of insulin restriction and omission are alarmingly high among young patients with T1D, especially females. ${ }^{41}{ }^{42}$ Females were significantly more concerned about taking insulin in the current study, underlining the importance of addressing insulin concerns clinically. Increased knowledge about attitudes toward insulin among males and females, and their impact on insulin administration may help guide clinicians in how they can motivate adolescents with T1D to appropriate self-care and sufficient supply of insulin.

As for coping strategies, females generally tended to score slightly higher (indicating positive coping) on each of the subscales in our study. This is in line with Skre $e t a l{ }^{34}$ who adapted and validated the Norwegian version of the ACOPE. Further, the current study identified significant gender differences on two of the ACOPE subscales: being social and solving family problems. This is 
also consistent with the findings of Skre et al. However, they additionally reported that females scored significantly higher than males on the subscale seeking diversion. Mean scores for males and females on the five subscales were generally very similar for these two studies of Norwegian adolescents, implying that our young T1D population is comparable to their healthy peers in terms of coping strategies. Differences in coping strategies between males and females are also reported in previous research. One meta-analysis revealed that females were more likely to engage in most coping strategies than males, but especially strategies involving verbal expressions to others of the self-to seek emotional support or to ruminate about problems. ${ }^{43}$ This is in concordance with our finding that females scored significantly higher than males on being social and solving problems in the family. On the contrary to what one might expect, these two subscales were not significantly associated with $\mathrm{HbA1c}$ in a previous study. Rather, the only ACOPE subscale significantly associated with higher HbAlc was 'ventilating negative feelings' (negative coping) among females, but not in males. $^{8}$

The study design was strengthened by the collaboration with the NCDR, which ensures clinical data are qualitycontrolled and complete for $95 \%$ of the total population of young patients with T1D in Norway. ${ }^{24}$ However, a main limitation of the study involves the self-reported data and the response rate of $12 \%$. Notwithstanding this limitation, very few significant differences were found between our participants and the background population in the Norwegian Childhood Diabetes Register (NCDR), except for somewhat higher age at T1D onset, slightly lower HbA1c levels and somewhat fewer episodes of diabetes ketoacidoses. In addition, a higher percentage of our participants used insulin pump compared with the T1D background population. This might indicate that our subgroup is slightly healthier than the rest of the population, although the effect sizes were small. We also recruited from hospitals around Norway across a large geographic area, which facilitates generalizability.

Clinical implications can be drawn from this study. Assessing and addressing psychological barriers to optimal insulin therapy may be a clinically important starting point for treatment, and a possible supplement to standard somatic T1D care. Normative data on such measures may facilitate interpretation of individual scores, although it should be noted that the mean scores reported in the current study are at a group level, and that individuals may score differently, regardless of their gender. An integrated multidisciplinary treatment approach which includes psychological aspects might broaden our understanding of why only one-third of adolescents currently meet the international treatment target of $\mathrm{HbAlc}<7.5 \%$ and may potentially contribute to better treatment and consequently reduced risk of serious diabetes late complications. The consistent finding of gender differences across the psychological measures implies that a tailored treatment approach for males and females with T1D may be warranted. Future studies are recommended to develop and test interventions designed to change illness perceptions, insulin beliefs, and to facilitate coping to improve T1D selfmanagement and outcomes.

Acknowledgements The authors thank Deborah L Reas for proofreading the manuscript.

Contributors LW planned the study, collected data, analyzed the data, and wrote the manuscript. LB collected data, and contributed to the data analysis and to the manuscript. TS is the leader of the Norwegian Childhood Diabetes Registry (NCDR), contributed to the planning of the study, collected clinical data with the NCDR, and contributed to the manuscript. KD-J was one of the initiators of the NCDR, and contributed to the planning of the study and to the manuscript. ØR supervised LW, contributed to the planning of the study, and contributed to the manuscript.

Funding The Research Council of Norway funded this work. The Norwegian Childhood Diabetes Registry is fully funded by the Health Region South-East.

Competing interests None declared.

Patient consent Obtained.

Ethics approval Regional Committees for Medical and Health Research Ethics.

Provenance and peer review Not commissioned; externally peer reviewed.

Data sharing statement No additional data are available.

Open Access This is an Open Access article distributed in accordance with the Creative Commons Attribution Non Commercial (CC BY-NC 4.0) license, which permits others to distribute, remix, adapt, build upon this work noncommercially, and license their derivative works on different terms, provided the original work is properly cited and the use is non-commercial. See: http:// creativecommons.org/licenses/by-nc/4.0/

\section{REFERENCES}

1. Silverstein J, Klingensmith G, Copeland K, et al. Care of children and adolescents with type 1 diabetes: a statement of the American Diabetes Association. Diabetes Care 2005;28:186-212.

2. Anderson RJ, Freedland KE, Clouse RE, et al. The prevalence of comorbid depression in adults with diabetes: a meta-analysis. Diabetes Care 2001;24:1069-78.

3. Barnard KD, Skinner TC, Peveler R. The prevalence of co-morbid depression in adults with type 1 diabetes: systematic literature review. Diabet Med 2006;23:445-8.

4. Bernstein CM, Stockwell MS, Gallagher MP, et al. Mental health issues in adolescents and young adults with type 1 diabetes: prevalence and impact on glycemic control. Clin Pediatr (Phila) 2013:52:10-15.

5. Mannucci E, Rotella F, Ricca V, et al. Eating disorders in patients with type 1 diabetes: a meta-analysis. J Endocrinol Invest 2005;28:417-19.

6. Nielsen S. Eating disorders in females with type 1 diabetes: an update of a meta-analysis. Eur Eat Disord Rev 2002;10:241-54.

7. Brierley S, Eiser C, Johnson B, et al. Eating problems in adolescents with Type 1 diabetes: a systematic review with meta-analysis Diabet Med 2012;29:677-81.

8. Wisting L, Bang L, Natvig $\mathrm{H}$, et al. Metabolic control and illness perceptions in adolescents with type 1 diabetes. $J$ Diabetes Res 2015;501:456340

9. Wisting L, Bang L, Skrivarhaug T, et al. Adolescents with type 1 diabetes - the impact of gender, age, and health-related functioning on eating disorder psychopathology. PLOS ONE 2015;10:e0141386.

10. Hopman P, Rijken M. Illness perceptions of cancer patients: relationships with illness characteristics and coping. Psychooncology 2014;24:11-18.

11. Foxwell R, Morley C, Frizelle D. Illness perceptions, mood and quality of life: a systematic review of coronary heart disease patients. $J$ Psychosom Res 2013;75:211-22.

12. Edwards R, Suresh R, Lynch S, et al. Illness perceptions and mood in chronic fatigue syndrome. J Psychosom Res 2001;50:65-8. 
13. Holliday J, Wall E, Treasure J, et al. Perceptions of illness in individuals with anorexia nervosa: a comparison with lay men and women. Int J Eat Disord 2005;37:50-6.

14. Mc Sharry J, Moss-Morris R, Kendrick T. Illness perceptions and glycaemic control in diabetes: a systematic review with meta-analysis. Diabet Med 2011;28:1300-10.

15. McGrady ME, Peugh JL, Hood KK. Illness representations predict adherence in adolescents and young adults with type 1 diabetes. Psychol Health 2014;29:985-98.

16. Grace SL, Krepostman S, Brooks D, et al. Illness perceptions among cardiac patients: relation to depressive symptomatology and sex. $J$ Psychosom Res 2005;59:153-60.

17. Pesut D, Raskovic S, Tomic-Spiric V, et al. Gender differences revealed by the Brief IIIness Perception Questionnaire in allergic rhinitis. Clin Respir J 2014:8:364-8.

18. Broadbent E, Donkin L, Stroh JC. Illness and treatment perceptions are associated with adherence to medications, diet, and exercise in diabetic patients. Diabetes Care 2011;34:338-40.

19. Brod M, Kongso JH, Lessard S, et al. Psychological insulin resistance: patient beliefs and implications for diabetes management. Qual Life Res 2009;18:23-32.

20. Peyrot M, Skovlund SE, Landgraf R. Epidemiology and correlates of weight worry in the multinational Diabetes Attitudes, Wishes and Needs study. Curr Med Res Opin 2009;25:1985-93.

21. Graue M, Wentzel-Larsen T, Bru E, et al. The coping styles of adolescents with type 1 diabetes are associated with degree of metabolic control. Diabetes Care 2004;27:1313-17.

22. Matud MP. Gender differences in stress and coping styles. Pers Indiv Differ 2004;37:1401-15.

23. Rosario M, Shinn M, Mørch H, et al. Gender differences in coping and social supports: testing socialization and role constraint theories. J Community Psychol 1988;16:55-69.

24. Monami M, Lamanna C, Marchionni N, et al. Continuous subcutaneous insulin infusion versus multiple daily insulin injections in type 1 diabetes: a meta-analysis. Acta Diabetol 2010;47 (Suppl 1):77-81.

25. Hilliard ME, Mann KA, Peugh JL, et al. How poorer quality of life in adolescence predicts subsequent type 1 diabetes management and control. Patient Educ Couns 2012;91:120-5.

26. Petitti DB, Klingensmith GJ, Bell RA, et al. Glycemic control in youth with diabetes: the SEARCH for diabetes in Youth Study. J Pediatr 2009;155:668-72.e1-3.

27. Skrivarhaug T, Stene LC, Drivvol AK, et al. Annual report 2013, the Norwegian Childhood Diabetes Registry, 2014.

28. Broadbent $\mathrm{E}$, Petrie KJ, Main J, et al. The brief illness perception questionnaire. J Psychosom Res 2006;60:631-7.
29. Weinman J, Petrie KJ, Moss-morris R, et al. The illness perception questionnaire: a new method for assessing the cognitive representation of illness. Psychol Health 1996;11:431-45.

30. Moss-Morris R, Weinman J, Petrie K, et al. The Revised Illness Perception Questionnaire (IPQ-R). Psychol Health 2002;17:1-16.

31. Horne R, Weinman J. Patients' beliefs about prescribed medicines and their role in adherence to treatment in chronic physical illness. $J$ Psychosom Res 1999;47:555-67.

32. Jonsdottir $\mathrm{H}$, Friis $\mathrm{S}$, Horne R, et al. Beliefs about medications: measurement and relationship to adherence in patients with severe mental disorders. Acta Psychiatr Scand 2009;119:78-84.

33. Patterson J, McCubbin $\mathrm{H}$. A-Cope: adolescent coping orientation for problem experiences. In: McCubbin HI, Thompson Al, McCubbin MA, eds. Family assessment inventories for research and practice. 2nd edn. Madison, WI: University of Wisconsin Madison, 1991.

34. Skre I, Arnesen Y, Breivik C, et al. Mestring hos ungdom: Validering av en norsk oversettelse av Adolescent Coping Orientation for Problem Experiences. Tidsskr Norsk Psykologforening 2007;3:236-47.

35. Kuczmarski RJ, Ogden CL, Grummer-Strawn LM, et al. CDC growth charts: United States. Adv Data 2000;314:1-27.

36. Cohen J. Statistical power analysis for the behavioural sciences. 2nd edn. Hillsdale, NJ: Erlbaum, 1988.

37. Fortenberry KT, Wiebe DJ, Berg CA. Perceptions of treatment control moderate the daily association between negative affect and diabetes problems among adolescents with type 1 diabetes. Psychol Health 2012;27:294-309.

38. Baines T, Wittkowski A. A systematic review of the literature exploring illness perceptions in mental health utilising the self-regulation model. J Clin Psychol Med Settings 2013;20: 263-74

39. Nielsen S, Emborg C, Molbak AG. Mortality in concurrent type 1 diabetes and anorexia nervosa. Diabetes Care 2002;25:309-12.

40. Belendez M, Hernandez-Mijares A. Beliefs about insulin as a predictor of fear of hypoglycaemia. Chronic IIIn 2009;5:250-6.

41. Goebel-Fabbri AE, Fikkan J, Franko DL, et al. Insulin restriction and associated morbidity and mortality in women with type 1 diabetes. Diabetes Care 2008;31:415-19.

42. Wisting L, Froisland DH, Skrivarhaug T, et al. Disturbed eating behavior and omission of insulin in adolescents receiving intensified insulin treatment: a nationwide population-based study. Diabetes Care 2013;36:3382-7.

43. Tamres LK, Janicki D, Helgeson VS. Sex differences in coping behavior: a meta-analytic review and an examination of relative coping. Pers Soc Psychol Rev 2002;6:2-30. 